\title{
ESTADO E ADMINISTRAÇ̃̃O PÚBLICA: O BRASIL E A LÓGICA CÍCLICA ESTAMENTAL PERANTE A CONCRETIZAÇÃO DA CIDADANIA, EFETIVIDADE DE DIREITOS SOCIAIS E O DIREITO FUNDAMENTAL À BOA ADMINISTRAÇÃO
}

\author{
Isaac Ronaltti Sarah da Costa Saraiva ${ }^{I}$
}

\section{RESUMO}

A temática da complexa relação que se trava no Brasil em relação à aplicação dos Direitos Sociais, a superação de realidades históricas cíclicas advindas do processo de colonização peculiar ocorrido em nossas terras, e, ainda, a atual crise institucional dos Estados modernos parece afetar toda a ideia de Estado e sua organização construída no Ocidente, após as Revoluções Burguesas e como saldo dos movimentos liberais do século XVIII. Este trabalho pretende fazer um diálogo entre questões referentes à administração pública, supremacia judicial, a questão da eficiência e o Direito Fundamental à Boa Administração.

Palavras-chave: Direitos Fundamentais; Direito à boa administração; Estado; Administração Pública; Estamento.

\section{STATE AND PUBLIC ADMINISTRATION: BRAZIL AND THE STATE CYCLICAL LOGIC BEFORE THE CONCERTATION OF CITIZENSHIP, EFFECTIVENESS OF SOCIAL RIGHTS AND THE FUNDAMENTAL RIGHT TO GOOD ADMINISTRATION}

\begin{abstract}
The issue of the complex relationship in Brazil with respect to the application of social rights, the overcoming of cyclical historical realities arising from the peculiar colonization process that took place on our lands, and the current institutional crisis of modern states seems to affect all the idea of State and its organization built in the West, after the Bourgeois Revolutions and as the balance of the liberal movements of the eighteenth century. This work intends to make a dialogue between questions related to public administration, judicial supremacy, the question of efficiency and the Fundamental Right to Good Administration.
\end{abstract}

Keywords: Fundamental rights; Right to good administration; State; Public administration; Estate.

\footnotetext{
${ }^{1}$ Mestrando em Direito Público pela Universidade do Vale do Rio dos Sinos - UNISINOS (CAPES 06). Bolsista do Programa de Excelência Acadêmica CAPES/PROEX. Graduado em História pela Universidade Federal de Rondônia (2003-2006). Bacharel em Direito pela União Educacional do Norte (2009-2014). Especialista em Didática e Docência no Ensino Superior pela União Educacional do Norte - UNINORTE (2007-2008). Especialista em Processo Civil e Direito Civil pela União Educacional do Norte - UNINORTE (2013-2014). Especialista em Direito Penal pela Damásio de Jesus (2017-2018). Endereço Eletrônico: isaacronaltti.saraiva@gmail.com
} 


\section{INTRODUÇÃO}

"Um Estado que muito promete e pouco cumpre" - as palavras do Professor Darci Guimarães Ribeiro (2010.p.105) sintetizam um pouco da complexa relação que se trava no Brasil em relação a aplicação dos Direitos Sociais, a superação de realidades históricas cíclicas advindas do processo de colonização peculiar ocorrido em nossas terras, e, ainda, a atua crise institucional dos Estados modernos - que longe de ser um problema só do Brasil, parece afetar toda a ideia de Estado e sua organização construída no Ocidente, após as Revoluções Burguesas e como saldo dos movimentos liberais do século XVIII.

A proposta deste trabalho se insere na discussão inicial da lógica patrimonialista e estamental trabalhada especialmente na obra de Raimundo Faoro, em os Donos do Poder. Por conseguinte, tratar-se-á da complexa relação entre o Estado Democrático de Direito e a inclusão de Direitos Sociais no pós-guerra, a relação destes Direitos originalmente inseridos em nossa Constituição a partir de 1934, e os reflexos e complexidades surgidas a partir da Constituição de 1988. Trataremos também da questão da supremacia judicial, a questão da discussão do ativismo judicial e os reflexos deste debate na questão da eficiência da aplicação de Direitos Sociais no Brasil.

Por fim, apresentaremos um quadro de pensadores que trabalham o princípio do Direito Fundamental à Boa Administração e algumas formas de compreensão contemporânea direcionada a contribuir no processo de maior participação popular, promoção da "sindicabilidade" dos atos do Estado e da Administração Pública pela população, e o desenvolvimento de um contexto democrático que viabilize e promova a eficiência da promoção dos Direitos Sociais em nosso país.

Metodologicamente, este trabalho se apoiará na revisão e na pesquisa de referências bibliográficas.

\section{1 - O PATRIMONIALISMO E O ESTAMENTO NO PROCESSO DE FORMAÇÃO DO BRASIL E SEUS REFLEXOS NA ADMINISTRAÇÃO PÚBLICA - AS LIÇÕES E OS LIMITES DE RAIMUNDO FAORO, EM OS DONOS DO PODER}

Os Donos do Poder de Raimundo Faoro explica em uma incrível abordagem que passeia por mais de 6 séculos - pontuados que percorrem desde a formação do Brasil até o Estado Novo de Getúlio Vargas - tratando a respeito da origem do patrimonialismo 
estamental no Brasil. Através de um remonte histórico e sociológico analisa processo de desenvolvimento político-administrativo e institucional do Brasil.

Inicia explicando que, o reinado da Casa de Aviz implantou uma estrutura administrativa no interior de Portugal que visava tão somente a sua própria manutenção - uma estrutura que ficaria conhecida como Monarquia Patrimonial. A Revolução Portuguesa do Mestre de Avis - uma revolução construída a partir de um processo negociado entre Nobreza e Rei - essa seria em tese, a origem da formação daquilo que foi conceituado como Estamento que reúne em seu interior: Estado, Grupos políticos, econômicos e Instituições Privadas, legitimadas pelo Estado e pelas Tradições, formando o estado patrimonial estamental fechado em si. O Estamento pensa no Estado e o Estado só pensa em si, preocupando-se unicamente com o bem estar e a manutenção do modus operandi do Estamento.

Faoro, utilizando bases metodológicas e historiográficas do Weberianismo e pinceladas do Marxismo - algo que será profundamente criticado posteriormente ${ }^{2}-$ aprimora os conceitos de "Estamento" e "Patrimonialismo". Faoro, embora não cumpra fidedignamente a análise do Brasil a partir de uma lógica onde o Estado é analisado a partir de sua estrutura, semelhante ao que fez Florestan Fernandes, e a nação é instrumentalizada a sua maneira por uma análise weberiana, embora negue, e ainda admita que Weber tenha sido importante teórico em sua formação acadêmica, pelo próprio uso dos léxicos com palavras como "estamental" e "patrimonialismo", torna-se impossível não reconhecer a influência Weberiana em sua obra. Sua obra tenta chamar a atenção para um processo de desenvolvimento da nação brasileira a partir de um traço singular de formação de uma classe dirigente sem conexão com a base - uma classe que se renova dentro dela própria - em termos a síntese daquilo que Faoro tenta conceituar como "Estamento": como um fenômeno de circulação das elites.

Aqui, abrimos um parêntese para salientar que, embora muito criticado por essa lógica cíclica, ás vezes aparentando ser algo instransponível, acreditamos que a principal missão de

\footnotetext{
2 Quanto as principais críticas dos marxistas a obra de Faoro podemos salientar que, Faoro foi acusado de, embora analisar estruturas de Estado, não se ateve ao mais importante para aqueles que analisam o capital: a análise estrutural econômica. Um segunda crítica a Faoro seria que o mesmo não analisou super estruturas determinadas, o que levaria um choque quanto a tese marxista que analisou o Brasil em seu passado colonial como feudal - isso se torna crítico principalmente por Faoro não identificar o Feudalismo no Brasil, mas um Patrimonialismo dirigido pelo Estamento que, conceitualmente e em substância e características seria amplamente distinto das características do período feudal - ideias de base originalmente Weberianas.
} 
Faoro fosse verdadeiramente chamar atenção para uma denúncia básica e grave: o Estado Patrimonial Estamental teria silenciado o desenvolvimento histórico do Brasil como nação, passando apenas a reproduzir o modelo português com todos os seus vícios e incoerências. Quiçá, o que talvez Raimundo Faoro intentasse promover ruptura tal que separasse os conceitos de Estado e Nação - que até então, eram sinônimos indissociáveis - sendo que o primeiro sempre se fazia pensar ser o segundo.

A ruptura proposta e analisada em alguns momentos históricos por Faoro curiosamente os Donos do Poder se concentra quase que essencialmente no período histórico do Brasil Império ${ }^{3}$ - alerta que em alguns momentos este "Estado patrimonial" fora contestado: a exemplo de Recife em 1817, durante a Revolução Pernambucana, e a Confederação do Equador, em 1824, movimentos que reivindicavam certa autonomia, contestação das bases da monarquia e que apresentavam tônicas de ideais republicanos ${ }^{4}$; narra ainda uma série de episódios na História do Brasil onde o Estamento fora contestado: Golpes de Estado, Militares no Poder, Coronelismo - momentos estes assistidos de forma passiva por uma nação sem voz.

A Coroa portuguesa conseguiu na Península Ibérica durante o processo de guerras contra os sarracenos e espanhóis, formar imenso patrimônio rural - não existia público e privado, tudo era de certa forma privativo do príncipe e da coroa. Os estamentos basicamente eram formados por reis que mandavam, orbitando nestes o clero e súditos que obedeciam. Ao contrário de outros processos evidenciados na Europa após a Revolução Francesa, em parte da península ibérica e nas colônias portuguesas, em razão do poder centralizador do rei, não formou-se uma camada de nobres proprietários, não desenvolveu-se também uma burguesia autônoma que contestasse o Poder do Rei a partir de ideais essencialmente liberais, por conseguinte, o desenvolvimento de uma classe operária também foi afetada, se estendendo essa realidade no reino nas demais colônias vinculadas a Coroa - especialmente o Brasil - um sistema intermediário baseado na Monarquia Agrária, que se difere do Feudalismo, não é tão flexível quanto o Capitalismo, e nem tão rígido quanto são hoje as castas da sociedade indiana. Tratava-se de um principado patrimonial - na monarquia patrimonial o principado

\footnotetext{
${ }^{3}$ Sistema político é conduzido pelas seguintes características: Centralização articulada, vitaliciedade, voto manipulado, entidades feitas de vento - nessa lógica, nação, povo, agricultura e comércio obedecem a esta lógica - talvez por isso o autor concentre tanto sua obra no século XIX.

${ }^{4}$ A Confederação do Equador de forma singular foi um movimento que abraçou uma maior participação de uma boa parte do Nordeste brasileiro.
} 
funciona como uma empresa a serviço do rei, alimentados por uma rede patriarcal. Essa teia ${ }^{5}$ de relações se refletia em todos os campos da sociedade, desde a formação e desenvolvimento das estruturas administrativas, de suporte político, fiscal e militar.

Um dos principais traços da Revolução Francesa foi a quebra da rigidez e a impossibilidade anteriormente existente do fluxo de ascensão existente entre as classes de uma sociedade. O protagonismo da burguesia, fez com que o ideal de ascensão passasse a ser o motor da lógica de funcionamento de uma sociedade que não era mais estática, não se subjugava a estamentos, não era mais baseada apenas em teias de relações nobiliárquicas, muito menos baseada apenas em tradições e vínculos familiares, mas em uma realidade em que aquele que detinha o capital, ou podia conquista-lo passava a se mover normalmente entre classes - talvez um dos principais problemas enfrentados por aqueles que defendiam a moribunda monarquia (ENTERRÍA, 2009)

Não bastasse, o cenário motivador da Revolução Francesa, que, às vezes, aparenta ser um evento isolado, único, modificador automático de uma ordem, mas como nos lembra Dieter Grimm (2006) e Garcia de Enterría (2009), revela um processo de mudanças sociais ocasionados por diversos fatores, sendo o principal deles o cenário da grande fome na França - cenários estes que não se desenvolveram com um simples apertar de um botão, mas que se desenrolaram ao decorrer de um processo demorado de décadas. De fato, a Revolução Francesa é um processo de mais de 50 anos que envolve o contexto da grande fome, questões religiosas e filosóficas que colocavam em cheque o poder e a incontestabilidade real, e, um cenário onde o poder divino passa a gravitar por novos paradigmas concentrado no poder econômico da burguesia, através do controle do capital. Ato seguinte, a burguesia precisa de controle e garantia para a sua atuação, cenário em que o Estado, a administração pública e as autoridades passam a encarar a conjuntura motivadora e da realidade, representada especialmente pela conjuntura de surgimento das constituições liberais.

A garantia e a proteção de direitos tornaram-se fatos de justiça que deveria atender a parâmetros racionais, estes baseados em notória previsibilidade visando organizar e legitimar o princípio da legalidade, que, diria aquilo que a administração pública poderia, deveria e estaria limitada a fazer - o que seria sintetizado no conceito de burocracia desenvolvido por Max Weber.

\footnotetext{
${ }^{5}$ Max Weber vai utilizar por diversas vezes em sua obra o termo "teia de relaçoes" para exemplificar melhor a ideia estrutural e de valores do estamento. Termo que também é reproduzido na obra de Eduardo Kossmann.
} 
Diferentemente, a Coroa Portuguesa estimulou e desenvolveu um sistema que mantinha uma estrutura peculiar de manutenção do reino e do estado, a partir de relações definidas, concentradas na manutenção do estamento e em aparelhos de Estado que tinha unicamente como justificativa de existência à manutenção da Coroa, e, abaixo dela, de todos aqueles que interligados viviam para manter a Coroa.

Um exemplo empírico disso seria: imaginemos uma pequena cidade em qualquer lugar desse país ${ }^{6}$, corriqueiramente, as grandes famílias de uma cidade controlam os principais expoentes econômicos destas comunas. São eles que são proprietários dos postos de gasolina, das mercearias e supermercados, das casas lotéricas, enfim, dos mais diversos campos econômicos de uma urbes. São estas famílias que empregam grande parte dos moradores, e, a partir desse ciclo de controle, estas famílias coordenam os processos eleitorais, "indicam" aos seus funcionários, "opções" de votos em períodos eleitorais, e, quase que repetidamente, são estas famílias que controlam a política destas cidades: empregam parentes, utilizam equipamentos e estruturas públicas em benefício próprio e se mantem em um estranho ritual de "fagocitose" do poder contínuo - utilizando-se do público e o confundindo-o com o privado.

Aqui, nos vale a transcrição Ipsis Litteris do trecho das próprias palavras utilizadas por Raimundo Faoro para descrever o estamento e sua relação com o Estado quando diz que, "O Estado, pela cooptação sempre que possível, pela violência se necessário, resiste a todos os assaltos..."

E continua (...) "Nele, o "povo" oscila entre a mobilização de passeatas sem participação política. Nele a "lei" é retórica e interessante e não lhe interessa; Nele, a "eleição", ainda que formalmente livre, lhe reserva opções que ele não formulou".

\section{1 - DO CONCEITO DE ESTAMENTO E PATRIMONIALISMO EM FAORO}

O Conceito de Patrimonialismo conceito organicamente originado no trabalho de Max Weber. Em síntese, seria uma forma de organização social distinta de Capitalismo e de forma semelhante, não igual ao Feudalismo. Nesse sistema, Estado funde a Soberania pública ao

\footnotetext{
${ }^{6}$ Ainda que vivamos em uma democracia e o contexto contemporâneo possua distinções consideráveis a lógica desenvolvida por Faoro, parte da representação daquilo que se pensa como Estamento, e que fora desenvolvido pela Coroa Portuguesa acaba sendo reproduzido cotidianamente em diversas cidades deste país e, mormente, em suas instituições "públicas” - usamos aspas aqui para salientar a tensa confusão originada em razão das relações estamentais, principalmente naquilo que se refere na questão da confusão do público com o privado.
} 
Patrimônio Privado, passando todos os bens econômicos de uma nação a ser extensão do Estado, servindo os mesmos apenas aos propósitos do Estado e não de seu povo. O Estado passa a ser objetivo, finalidade, pressuposto e objeto.

Quanto ao Conceito de Estamento, também com origem Weberiana, poderia ser sintetizado como sendo uma forma de estratificação social mais fechada que os conceitos de classes e mais aberta que o conceito de castas. Neste formato de estratificação, o indivíduo está obrigado a seguir um estilo de vida predeterminado, a partir de leis, normalmente vinculadas à honra. $\mathrm{O}$ estamento é representado temporalmente como originado no medievo, contemporâneo ao Feudalismo. Max Weber acaba por ampliar o conceito de estamento, sendo que mais do que ser sintetizado por classes como nobreza, clero, vassalos e servos, o estamento é representado por uma teia de relacionamentos que constitui um determinado poder, e, esse poder, passa a influir em todos os campos de atividade de um Estado.

\section{2 - VISÕES DISTINTAS DE UM MESMO BRASIL - OUTROS OLHARES A RESPEITO DA FORMAÇÃO POLÍTICA E SOCIAL DO BRASIL}

O estudo da formação política e social do Brasil desvela outras visões que transpassam os limites da leitura Estamental, mas que de forma simbiótica também se comunicam com a leitura de formação política e social idealizada na obra de Raimundo Faoro: desde a obra mais intima e psicológica de Sérgio Buarque de Holanda, passando pela leitura que permeia o Direito e a Política de Victor Nunes Leal e a leitura de uma visão privatista em face dos espaços e da administração pública brasileira, desenvolvida por Nestor Duarte, este último apontando tal realidade como um dos vetores mais nefastos para a consolidação da Democracia no Brasil.

Sérgio Buarque de Holanda (1978) afirma em Raízes do Brasil narra que a democracia enquanto ideal ou como prática política já nasceu aqui como um lamentável mal-entendido. A democracia tem assumido no Brasil. desde remotos tempos, um significado singular. No século XIX, diversos políticos tidos como liberais na época do império afirmavam seus anseios por uma democracia de "gravata lavada". Uma parte significativa das análises da forma de organização da política brasileira desde os seus primórdios tem destacado a ausência de condições mínimas para a existência da democracia no Brasil. Alguns trabalhos que podem ser considerados clássicos do pensar sobre o Brasil cruzam fazem com que obras como "Os donos do poder", de Raimundo Faoro se completem com a interessante análise mais intimista 
produzida em Raízes do Brasil por Sérgio Buarque. E aqui abrimos parêntese para o debate da obra de Faoro com alguns outros autores que parecem construir o cenário da análise feita por Sérgio Buarque de Holanda quando afirma que a Democracia no Brasil surgiu como um mal entendido. A democracia como um mal entendido ${ }^{7}$ é a expressão da confluência de falta de bases econômicas, políticas, culturais e sociais, tanto para a sua existência quanto pela "facilidade com que se alimentam (alguns intelectuais) de doutrinas dos mais variados matizes e com que sustentam, simultaneamente, as convicções mais dispares.".

Raimundo Faoro, em Os donos do poder, mostra que a formação do Estado brasileiro e a forma de domínio patrimonial e burocrática que adentraram no âmago da organização política e administrativa brasileira desde a época da colônia, conduziram a uma exorbitante centralização política e a uma combinação de privatismo e arbítrio que resultaram em "exercício privado de funções públicas e (..) exercício público de atribuições não legais"(FAORO, 1989: 182).

Faoro aparentemente por se aventurar por uma infinidade de campos científicos em sua análise, talvez tenha se colocado a mercê da crítica dos ferrenhos marxistas, principalmente por sua obra apresentar uma conjuntura que teleologicamente aparenta estar desconexa e existir sem o povo - e talvez isso seja o contexto da crítica, e por vezes, mal interpretada, por entender que estaria Faoro a defender uma ordem cíclica estamental, por vezes insuperável - o que aparentemente é apenas uma denúncia de um processo de "desenvolvimento" que precisa naturalmente ser superado.

Vale ressaltar os limites da análise de Faoro para o cenário pós constituinte que se formou no Brasil, mas que de certa forma, sem a exigência draconiana de cobrar da análise de Faoro uma explicação total para todas as conjunturas, algumas boas obras contemporâneas a Faoro, unidas a obra de Sérgio Buarque contam a partir de realidades distintas e contextos diversificados singularidades que de certa forma se completam e concretizam parte da na análise da formação política do Brasil autônomo entre elas, "Coronelismo, enxada e voto", de Victor Nunes Leal (2012) que explica a formação das relações de poder a partir do poderio militar estabelecido e centralizado nos Coronéis do nordeste, que passaram a receber tal título oficialmente por serem responsáveis pela proteção dos vilarejos e pela organização de

\footnotetext{
${ }^{7}$ Sérgio Buarque se refere a uma nação que embora tenha encerrado o escravismo e se desligado dos colonizadores, não conseguiu criar bases para a construção de um capitalismo local, massa de consumidores e costumes que pudessem alterar gradativamente as relações de poder.
} 
agrupamentos de defesa armada - mostrando inclusive a relação construída no que se refere a interferência no voto, na oferta de trabalho e nas mais pitorescas relações do cotidiano.

Outra grande obra que de certa forma dialoga com Faoro é "A ordem privada e a organização política nacional", de Nestor Duarte (1997) quando destaca o enorme vigor do poder privado no Brasil desde os tempos coloniais; o qual se cristalizou como um verdadeiro empecilho para a democratização do país.

\section{2 - A EFICIÊNCIA NA APLICAÇÃO DE DIREITOS SOCIAIS APÓS A CONSTITUIÇÃO DE 1988 - DEMOCRACIA, JURISDIÇÃO $\quad$ E ADMINISTRAÇÃO PÚBLICA.}

Os Direitos sociais surgem como conquista do fim do século XIX, mas efetivamente passam a compor constituições em 1917 com a Constituição Zapatista no México, em 1919, com a Constituição de Weimar na Alemanha, e originariamente em 1934 no Brasil (KRELL, 2002 p.19)

A experiência da Constituição de Weimar é uma das mais debatidas, vez a mesma ser para a época um exemplar ousado e moderno de atribuições positivas ao estado perante o cidadão, embora seja discutido de forma semelhante que, a ineficácia na consolidação dos Direitos apresentados na Carta de Weimar, tenham se transformado em frustração e servidor de combustível para o fortalecimento de movimentos como o Nazismo. O momento vivido pós-constituição de 1988 é, sem dúvida nenhuma singular. Para que tratemos a respeito da questão da eficiência e do contexto de aplicação dos direitos sociais e os novos caminhos desvelados por uma democracia recente, além dos novos paradigmas apresentados a jurisdição e a toda administração pública, saída de um regime ditatorial militar e neófita em uma realidade de uma carta de diversos direitos que, em momentos, pareciam desconsiderar as peculiaridades de um país de modernidade tardia, interessante tratarmos de temas como democracia e supremacia judicial e novas abordagens de participação democrática da população no contexto de aplicação de direitos sociais no estado democrático de Direito.

Ainda sobre Faoro, ao romper de diversos movimentos no início do século XIX, no Brasil, rapidamente movimentos representados por uma elite local que esboçava uma contestação originalmente brasileira - embora resquícios e manifestações de movimentos de contestação tenham se apresentado durante todo o Império - foram suprimidos pela vinda da família real para o Brasil. 
Mesmo com o advento da República, pouca coisa muda, apenas as entrada dos militares dentro da estrutura, que, sutilmente continua a ser mantida pela Oligarquia cafeeira, através da política de Governadores - ondes os mesmos se alternam.

É com Getúlio Vargas que se inicia efetivamente a discussão das bases de formação originalmente de um Brasil - muito embora, isso também não tenha significado o rompimento com a estrutura estamental, mas observasse que a estrutura burocrática brasileira começa a denotar tensão entre o Estado e a Nação - o que na lógica estamental da Coroa Portuguesa sempre aparentou tratar-se da mesma coisa -, vez ser o Estado a ponta oposta do Governo, e, a nação, a ponta oposta do povo, começa a ser contestada por uma massa intelectual orgânica da qual o próprio Faoro é um dos expoentes - e por novos contextos político-administrativos advindos com o Estado Novo e especialmente, na Constituição de 1934, que passava a incorporar mais densamente a presença de Direitos Sociais.

Consideradas as eventuais críticas a Vargas, é com ele que apresentasse um projeto de Brasil em que, mesmo que de forma tímida aparece a cara do local, do povo, do trabalhador, do camponês - e isso também não significa dizer que a forma como se deu tenha sido algo efetivamente orquestrado pelo Governo Vargas, mas talvez por um processo de amadurecimento natural de grupos dentro do tecido social, especialmente aqueles representados por movimentos de esquerda, que acabavam por funcionar como pressão para o governo, e este, como resposta tivesse que incorporar medidas que servissem de mecanismo de contenção destes próprios movimentos.

Passada a Era Vargas, e a reforma protagonizada pelo Estado Novo, que, de forma semelhante também significou o conceber de um novo engendramento para as instituições públicas brasileiras, o Brasil se viu anos depois sucumbindo ao Regime Militar. Mais que tratar de acesso a direitos sociais - alguns deles surgidos na Era Vargas - o Brasil se via no dilema da discussão da cobrança de responsabilidades negativas do Estado perante seus cidadãos, essencialmente a luta por direitos individuais que, por mais de duas décadas, foram cerceados pelo Estado. Só com a Constituinte de 1988 é que passamos a relacionar-se com o Estado brasileiro a partir de uma ótica essencialmente voltada para o contexto das obrigações positivas por parte do Estado - muito mais do que apenas indicar o trabalho, o Estado passa a consolidar uma série de medidas e direitos sociais que passam a figurar como direitos fundamentais, mas que até então não eram encarados como ferramentas indispensáveis de qualquer cidadão brasileiro. 
2.1 - NORMAS PROGRAMÁTICAS, SUPREMACIA JUDICIAL E A EFICIÊNCIA NA APLICAÇÃO DE DIREITOS SOCIAIS.

Segundo Pontes de Miranda (2002), as normas constitucionais deveriam funcionar como programa, com a finalidade de atender a necessidade do parlamento em editar leis e a responsabilidade da administração e o judiciário no compromisso de aplica-las, embora o que observamos passados 30 anos da Constituição Cidadã, ressalvadas algumas exceções, é que grande parte dos Direitos Sociais acabam por figurar como "meros simbolismos" (KRELL, 2002, p.25) - o que nos insere em um debate contemporâneo a respeito da eficiência das normas constitucionais na aplicação de Direitos Sociais. Mais que a positivação de Direitos, à Eficiência está ligada a mudanças nos valores culturais (KOSSMAN, 2015). Kossmann corrobora a tese de Faoro quanto à interferência nociva na administração pública brasileira do Patrimonialismo Estamental, mas em mesmo tempo, elenca nuances e tônicas para a superação daquilo que talvez, tenha se tornado vetor de uma das maiores críticas ao trabalho de Raimundo Faoro no clássico “Os Donos do Poder”: Kossman (2015) pontua que para compreender o princípio da Eficiência no Estado Brasileiro precisamos proceder uma imersão em conceito diretos como Direito, Democracia, Eficiência e Legitimidade. Nesta senda, a questão ética e as mudanças de valores de uma sociedade são mais importantes no que se refere ao caminho em direção à eficiência, que o simples adorno e inserção instrumental na Constituição.

Essa clareza de saber que a substância do princípio é muito mais importante que a própria norma expressa, pois é a função social desta substância que se visa atingir e não apenas um mero cumprimento de uma formalidade sem o devido atingir de objetivo da função social que motivou a existência de determinado princípio - a norma não existe para si, mas para um objetivo predeterminado e uma função social desejada. Kossman incita-nos a observar que, a Democracia mais que uma forma de governo, deve ser um conjunto de "valores".

Krell (2002) citando Canotilho e sua obra de 1982 que tratava a respeito da Constituição Dirigente e a vinculação do legislador, acreditava quase que teleologicamente, na tese de que normas programáticas constitucionais sobre os mais variados temas - saúde, educação, cultura - seriam suficientes para obrigar o legislador a implementar as respectivas 
leis ordinárias $^{8}$. Notadamente, este processo resultou em incontáveis situações de inconstitucionalidade por omissão. A influência da Carta Portuguesa na Constituição de 1988, fez com que mais recentemente, Canotilho viesse assumir que o modelo de Constituição Dirigente estaria falido, em razão principalmente da transformação de ordens jurídicas nacionais em questões parciais e regionalizadas.

O texto jurídico, o texto constitucional é um regulamente normativo que expressa o desenvolvimento social cultural de um povo - sendo meio de afirmação cultural de uma nação, espelho de seu patrimônio cultural e fundamento maior de suas esperanças. (HABERLE Apud KRELL, 2002). Talvez o legislar tenha se tornado mais básico que fazer cumprir a lei, e "normas exageradas eram estímulos aos donos do poder" para que cumprissem a esperança daqueles que teoricamente viriam a ser beneficiados (LOEWESNSTEIN Apud KRELL, 2002). O que acompanhamos no Brasil é uma profunda discussão a respeito do cumprimento de Direitos Sociais, e aqui, abrimos um parêntese para o debate daquele, que, entre os Direitos Sociais levanta o maior foco de debate - no caso a questão da saúde, especialmente a questão da utilização de ações judiciais usadas para obrigar o poder público a fornecer remédios e tratamentos. E não precisamos avançar muito para entrar em temas muito mais polêmicos e paradigmáticos que compõem o rol de direitos sociais, como, a exemplo, a questão da moradia.

Bobbio (1992) faz uma provocação que se relaciona diretamente com a efetividade dos Direitos Sociais pós-Constituição de 1988, quando pergunta “...direitos podem ser chamados assim, quando o reconhecimento destes e sua proteção são adiados?"

Barroso (2012) discorre no sentido de diagnosticar parâmetros e limites para o atendimento do mínimo possível no que se refere ao direito de acesso à saúde, respeitando os limites da separação de poderes e, normalmente, obedecendo a limites e rigores adstritos a preceitos da administração pública. Conceitos de Estado Democrático, Democracia e Separação de Poderes são trabalhados por Barroso, além de transitar por um debate a respeito do conflito de normas e princípios - costumeiramente evidenciada na relação que envolve as ações que objetivam o fornecimento de medicamentos.

Barroso desenvolve um breve histórico á respeito da inserção constitucional da saúde, pós-advento da influência do constitucionalismo e dos direitos sociais no pós-guerra. Esboça uma estrutura de moderação para a atuação e análise dos pedidos judiciais

\footnotetext{
${ }^{8}$ Muito semelhante ao defendido por Pontes de Miranda.
} 
relacionados a medicamentos, salientando que o judiciário não pode legislar ou aplicar diretamente políticas públicas, mas efetivamente cumprir a lei, respeitando a organização administrativa, os limites do princípio do mínimo possível, além de respeitar uma previsibilidade administrativa dos entes federados - permitindo uma organização que evite à superposição dos entes federados no que se refere a tal política pública - o não deferimento de medicamentos experimentais e a opção primordial a compostos farmacêuticos nacionais.

A aplicabilidade direta e imediata por juízes de direitos subjetivos plenos no que se refere a forçar a administração pública a fornecer remédios, perante a promessa constitucional da universalização dos serviços de saúde causa conjunturas que extrapolam a própria organização da administração pública e geram situações em que decisões emocionais passam a sofrer muito mais o filtro da moral que do próprio direito, "condenando a administração pública ao custeio de tratamentos irrazoáveis: inacessíveis, destituídos de essencialidade, medicamentos experimentais e de eficácia duvidosa.

Quanto a discussão da eficiência e o seu contexto dentro de uma democracia, Gargarella (2006) defende que o conceito de democracia representativa caminha lado a lado com o respeito à aplicação judicial de direitos sociais - abertamente uma visão pluralista. Insta salientar que tanto Barroso quanto Gargarella, em que pese à crítica ao Ativismo Judicial, procuram salientar as diferenças entre uma Democracia sob a égide de uma supremacia judicial - que sendo contra majoritária também é profundamente criticada - em relação à acusação da Revisão e do Ativismo Judicial. Ainda quanto à questão do Ativismo Judicial pensadores como Barroso defendem que a inércia política do Executivo e do Legislativo serve de pano de fundo para o fenômeno do Ativismo Judicial - onde a migração de obrigações legais dos demais poderes são lançadas a serem decididas pelo Judiciário, engenhosidade criativa que visa entre outras coisas afastar os Poderes Legislativo e Executivo de pautas que possam provocar impactos eleitorais, ou, movimentos contrários aos poderes pela opinião pública.

"Em casos politicamente custosos, os poderes Legislativo e Executivo podem, de um modo estratégico, por meio de uma inércia deliberada, abrir um espaço para a atuação ativista dos tribunais. Temas profundamente controvertidos, sem perspectiva de consenso na sociedade, tais como a abertura dos arquivos da ditadura militar, uniões homoafetivas, aborto, entre outros, têm os seus custos políticos estrategicamente repassados para os tribunais, cujos integrantes não precisam passar pelo crivo do voto popular após suas decisões". (YEPES, 2007.p.57) 
Alejandro Nieto (2005) faz um contraponto à obra de Roberto Garagarela, na medida em que, dialoga com as idéias quanto aos formatos de democracia, desde a democracia Pluralista (Mandsoniana), Democracia Populista e Democracia Deliberativa, especialmente, no que se refere às condições práticas para o exercício de uma democracia que seriam: tolerar a autonomia do individuo e dos caminhos que escolheu para si, e, em plano mais específico, dar garantias para que isso se processe. Em meio a isso, trazemos a obra do Espanhol, Alejandro Nieto que apresenta, a partir de uma intensa crítica, uma série de distorções vividas pelas côrtes e na administração pública espanhola, originada de um cenário de intervenção extrema da política na justiça e nas instituições públicas de forma geral - chegando ao ponto de compara-la a uma mera administradora dos interesses políticos. Mostra um distanciamento entre a figura de uma justiça imparcial e a realidade de Juízes justiceiros, além de denunciar um estranho ativismo movimentado a partir das pautas e agendas do Executivo Espanhol.

Essencialmente, a crítica de Nieto se insurge com um problema da contemporaneidade e um desequilíbrio manifesto de um sistema tripartite de distribuição do poder idealizado por Mostesquieu, que, talvez, não explique mais a conjuntura das democracias constitucionais (MORAIS, 2016). Em tempos de discussão do Ativismo Jurídico, Nieto chama ao debate de outro desequilíbrio nocivo: o controle político partidário da Justiça e sua interferência e consequente má prestação da administração pública. A questão básica da crítica feita ao ativismo jurídico, na busca desenfreada pela eficiência de Direitos Sociais é que seria ilegítima a conformação e decisão de tais demandas por impulso unilateral do Poder Judiciário, vez que tal postura atentaria contra a separação de poderes, e qual legitimidade teria o poder judiciário, como poder contra majoritário que é, para cancelar, alterar, ou impor a administração pública e aos demais poderes o cumprimento de decisões que naturalmente não estariam previamente contidas em um orçamento prévio. A argumentação contrária de pensadores como Barroso é que parte das decisões do judiciário se deu em tese ${ }^{9}$, a partir de uma ineficácia dos poderes legislativos e executivo no cumprimento racional de direitos constitucionais - o que essencialmente não seria um sofisma. Barroso, defendendo a visão dos mandados de otimização de Robert Alexy e o primado da ponderação, defende a partir de uma visão que não estaria sendo o poder judiciário ativista na falta dos

\footnotetext{
${ }^{9}$ Essa mesma visão também nos é apresentada na página 22 da obra de KRELL, Andreas J. Direitos Sociais e Controle Judicial no Brasil e na Alemanha - Os (Des)caminhos de um Direito Constitucional "Comparado". Sérgio Antônio Fabris Editor - Porto Alegre: 2002.
} 
demais poderes, e que existiriam barreiras que são obedecidas na medida em que se criam padrões para decisões.

\section{2 - O DESAFIO DA DEMOCRACIA E O APROFUNDAMENTO DE MECANISMOS DE PARTICIPAÇÃO POPULAR}

No tocante ao conceito de democracia, Dominique Rousseau (2016) traça uma linha do tempo iniciando na democracia grega, aquela decidida nas discussões na ágora, considerada direta, mas relegada a aqueles que eram considerados cidadãos na Grécia antiga. Avança quanto o conceito de democracia Representativa mais aprofundada em Max Weber, onde a sociedade elegeria mandatários responsáveis por representar os direitos e as opiniões dos grupos que compõem o tecido social, e, acrescenta mais uma visão a respeito da Democracia, que, seria a democracia Contínua ou, Democracia Radical.

Segundo Dominique Rousseau a democracia contínua/radical teria três características básicas: (i) A forma de sociedade não se limita a uma forma de Estado, pois o Estado organizado difere da sociedade democrática - mais que uma forma de estado a democracia contínua é uma forma de sociedade; (ii) A democracia contínua como espaço de desenvolvimento de regras: a partir de uma visão em que o sufrágio universal não é o elemento mais importante para identificar uma sociedade democrática, entendendo os limites e os problemas enfrentados na contemporaneidade quanto à crise de representatividade; (iii) Democracia Contínua como espaço de tensão de duas identidades de "povo": onde povo não se resume a entidade fictícia e virtual que todos normalmente costumam abusar do uso - a ideia de povo como cidadão, convivendo com os "representantes do povo", em um espaço de tensão que combine as atuais instituições de representação, sem que estas sufoquem ou aniquilem a representatividade do cidadão - não se sujeitando apenas a visão minúscula de democracia direta pela simples existência de referendos e plebiscitos no corpo constitucional. Nisso, o texto de Dominique Rosseau converge diretamente com os pontos abordados pelo Professor Bolzan de Morais e Guilherme Valle Brum em "Políticas públicas e jurisdição constitucional: entre direitos, deveres e desejos", pois, assim como Rosseau, discute questões peculiares a visão dos conceito de Legitimidade, Povo (assim como a ideia de "povo princípio" em Rosanvalon) e democracia.

Sincronicamente, ambos os textos conclamam "construção de novas fórmulas para a contemporaneidade pelos juristas", perante Novas tecnologias, novos riscos sociais, em 
contraponto a mecanismos decisórios da modernidade que são lentos em relação à contemporaneidade. O pano de fundo para a construção de ambas as críticas é definitivamente a crise de representatividade, o limite do pensamento de Montesquieu quanto a separação de poderes - insuficiente para explicar a fluidez e o engendramento necessário para os dias de hoje -, a construção de novas arenas de discussão da democracia, crise do Estado Social (ainda que este, no caso do Brasil, tenha sido falseado em razão de uma modernidade tardia).

Quanto ao debate da questão do Ativismo Judicial, o acesso à justiça e a omissão do legislativo, a falta de eficiência do setor público perante direitos sociais contribuíram diretamente para o surgimento de um judiciário protagonista - culminando esse processo na proposta de Emenda à Constituição ${ }^{\circ}$. 33, que, entre outras coisas suscitava a possibilidade do controle de decisões do STF pelo Congresso Nacional.

\section{3 - POLÍTICAS PÚBLICAS E O APROFUNDAMENTO DO DIREITO FUNDAMENTAL À BOA ADMINISTRAÇÃO NO BRASIL}

A discussão do Direito Fundamental à Boa Administração tem sido recorrente na academia na última década, muito embora, no Brasil ainda seja um ideal romântico - embora lutemos para que não caiamos no total ceticismo de considerar o direito a aplicação de direitos uma quimera, um alvo inalcançável, um oásis no deserto de injustiças que foram construídas no Brasil perante o seu povo.

Segundo Siegfried Magiera (2008), embasado no art. 41, da Carta de Direitos Fundamentais da União Europeia - a presente carta faz menção expressa ao Direito à Boa Administração - três são os componentes básicos consolidadores do Direito Fundamental à boa administração: o direito impreterível de ser ouvido, o acesso à informação e o direito à motivação das decisões - não só as jurídicas, como essencialmente também as administrativas: e fazemos esse aparte principalmente para lembrar do estranho juízo de valor que alguns fazem de que seriam de menor importância as decisões administrativas, quando, em verdade, é justamente o contrário, pois são estas últimas que normalmente afetam coletivamente e, em menor espaço de tempo, para o bem ou para o mal, a vida da população.

Segundo Juarez Freitas (2009), o Direito Fundamental à boa administração exercida através de políticas públicas possuem algumas características básicas para o seu bom funcionamento: ( $i$ ) Políticas públicas precisam ter propósitos; (ii) Políticas Públicas precisam ter motivação (fáticas e jurídicas); (iii) Políticas públicas precisam ser avaliadas (ações e 
omissões); (iv) Políticas públicas precisam ter resultados eficientes; O Estado precisa avaliar políticas públicas, para que seus benefícios venha gradativamente ultrapassar seus investimentos. Para isso, Juarez Freitas salienta que é necessária uma ruptura institucional com os elementos patrimonialistas e os naturais vícios administrativos advindos desta. Para tanto, necessário se faz a criação de modelos autônomos alheio a pretensões partidárias, baseados em atos discricionários vinculados. $\mathrm{O}$ administrador público tem o dever de oferecer boas razões (de fato e de direito) na implementação de políticas públicas. Para a consolidação do Direito Fundamental à Boa Administração, requer-se ambiente institucional - afastado do burocratismo proselitista. Estabelecimento de metas monitoráveis. Consolidação e enraizamento dos princípios da boa governança baseada na transparência, no controle participativo e na análise retrospectiva e prospectiva das ações implementadas.

Nesse viés, é preciso assumir a "sindicabilidade" como eixo norteador da boa administração, ao invés do histórico desleixo tradicional. Faz-se necessário também a quebra de paradigmas - especialmente de um predomínio senhorial, herança precípua do patrimonialismo, que sempre caminha em direção contrária à ativação de direitos fundamentais. Juarez de Freitas sugere algumas posturas e encaminhamentos para a superação no Brasil da lógica patrimonialista que atravanca tanto a jurisdição quanto a administração pública no caminho da construção daquilo que também é direito do cidadão e obrigação do Estado: o Direito à boa administração. Sugere:

(i) A discricionariedade administrativa no Estado Democrático de Direito deve estar vinculado a prioridades constitucionais, sob pena de se converter em arbitrariedade (seja por omissão ou por ação);

(ii) As políticas públicas devem ser entendidas como programas de Estado Constitucional (mais que ação de governo) - se sujeitando a sindicabilidade de vários participantes deste processo;

(iii) O Controle dos Atos Discricionários por surgir a partir de um juízo de valor, necessitam de motivação e análise de resultados, para que materializem as finalidades constitucionais;

(iv) A autoridade embora possua uma margem de mobilidade, não desfruta de liberdade pura para escolher consequências diretas e indiretas - uma perspectiva de alargamento das ferramentas de controle das decisões administrativas;

(v) A sindicabilidade desvela o poder racional de veto a impulsos políticos não universalizáveis;

(vi) O administrador público possui uma liberdade condicionada ao bom administrar essa flexibilidade surge como e para que o próprio administrador desenvolva suas funções com êxito, e não com a burocracia proscratinatória; 
(vii) A partir do primado do Direito Fundamental à Boa Administração, a agenda administrativa deve guiar-se para a real efetivação de prioridades constitucionais.

Segundo Arana (2013) para a consolidação inequívoca dos ideias que visam como objetivo o Direito Fundamental à boa administração, necessário se faz o desenvolver de uma nova engenharia, um novo desenho da administração pública em especial. Arana refuta a ideia básica desenvolvida no conceito de Burocracia por Max Weber a respeito dos moldes da administração. Ao contrapor o pensamento de Max Weber, Arana refuta a ideia de Weber de que uma das principais características da administração pública fosse justamente sua resistência a mudanças, e defende que uma boa administração pública deve ter como horizonte a melhor e a reflexão contínua de seus serviços para o cidadão, devendo, portando, a administração pública se adaptar as mudanças sociais e as necessidades prementes advindas das mudanças e dos contextos insurgentes de cada época. Arana entende que a administração pública nas sociedade avançadas é a chave que abre a porta rumo a satisfação de muitas necessidades, essas desenvolvidas através de políticas públicas.

Segundo Arana, a perseguida boa administração voltada para o cidadão deve se guiar por características básicas como: (i)Estar direcionada a servir a cidadania; (ii)Realizar seu trabalho com racionalidade; (iii)Justificar suas ações; (iv) Se orientar continuamente ao interesse legal.

Como já foi anteriormente exposto, parte dos muitos debates do Direito à Boa administração surgiram a partir da inclusão do respectivo direito na "Carta Europeia de los Derechos Fundamentales". O cidadão como finalidade da atuação da administração pública é, sem dúvida, o objetivo principal de voltado para aqueles que explicam a existência desta convenção nomeada de "Estado", e aqui, trazemos as palavras do Professor Ronald Dworkin (2006), que afastam a visão utilitarista e reforçam a visão da importância do cidadão como finalidade maior de um Estado: Toda vida desperdiçada, todo fracasso existencial é uma perda para a humanidade como um todo. O Estado, o Direito e a Sociedade devem contribuir, na maior extensão possível, para que o indivíduo desenvolva suas potencialidades e realize seu projeto de vida.

\section{CONSIDERAÇÕES FINAIS}

Ao decorrer desta breve incursão a respeito de temas tocantes ao Direito e a Administração Pública, fácil e perceber parte dos vícios que herdamos decorrentes do 
processo de colonização, mas que naturalmente, como tratamos no decurso do próprio texto e acreditamos que este seja a principal denúncia de Faoro quanto à lógica de reprodução cíclica do Estamento e da "Teia de Relações" que se manifestam na estrutura do Estamento.

Algumas das principais estruturas advindas da Revolução Francesa acabaram por não se desenvolver nas terras sobre influência portuguesa, devido a lógica de manutenção criada pela Coroa Portuguesa. Contudo, percebemos que ao decorrer do século XX, especialmente a partir do Estado Novo e a Constituição de 1934 com a inserção de direitos sociais no escopo constitucional brasileiro.

É a partir de 1988 que passamos a encarar a realidade de uma estrutura, em tese, voltada para o cidadão. Embora soframos para a efetivação dos Direitos Sociais e isso, gere um grande embate relacionado a questão da judicialização de Direitos Sociais e a atuação do Judiciário, por vezes intervindo e sendo intitulado de Ativista, aparenta que parte de alguns vícios denunciados por Faoro caminhamos para a superação, mas que necessariamente, isso se dará com a garantia e o acesso ao Direito à Boa Administração, e como bem identificado pelo francês Dominique Rousseau, e, pelo espanhol Rodríguez Arana, isso só será possível com a participação inequívoca da sociedade, do povo, do cidadão, exercendo e lutando por mecanismos que garantam a fiscalização, a sindicabilidade e a justificação contínua do poder público de como se dá o procedimento de escolha e eleição, bem como da aplicação, de políticas públicas voltadas a promoção de Direitos Sociais.

\section{REFERÊNCIAS}

BARROSO, L. R. Da falta de Efetividade à judicialização excessiva: direito à saúde, fornecimento gratuito de medicamentos e parâmetros para a atuação judicial. 2008

. Constituição, Democracia e Supremacia Judicial: direito e política no Brasil

Contemporâneo. Revista da Faculdade de Direito da UERJ, Rio de Janeiro, v.2, n.2, n.21, p.1 - 50, jan/jun. 2012;

BOBBIO, Norberto. O Futuro da Democracia: uma defesa das regras do jogo. $5^{\text {a }}$ Ed. Rio de Janeiro: Paz e Terra, 1992;

DUARTE, Nestor. A ordem privada e a organização política nacional - contribuição à sociologia política brasileira. $3^{a}$ Edição. Brasília. Ministério da Justiça, 1997;

FAORO, Raimundo. Os Donos do Poder - Formação do Patronato Político Brasileiro. Rio de Janeiro - Editora Globo, 1958;

FREITAS, Juarez. O controle dos atos administrativos e os princípios fundamentais. 4 ed. São Paulo: Malheiros, 2009; 
GARCÍA DE ENTERRÍA, Eduardo. La lengua de los Derechos. La Formación del Derecho Público europeo tras la Revolución Francesa. Madrid|: Alianza, 1995;

GARGARELA, Roberto; ¿Democracia deliberativa y judicialización de los derechos sociales?

Periódico Perfiles Latino Americanos; $n^{\circ} .28$ - Julio-Diecembre/2006;

GRIMM, Dieter. Política e Direito. In: Constituição e política. Tradução de Geraldo de Carvalho. Belo Horizonte: Del Rey, 2006. p. 3- 20.(Capítulo 01);

HOLANDA, Sérgio Buarque de. Raízes do Brasil. 12. ed. Rio de Janeiro: José Olympio, 1978;

KOSSMANN, Edson Luís. Constitucionalização do princípio da eficiência na administração pública. Porto Alegre: Sergio Antonio Fabris ed., 2015;

KRELL, Andreas J. Direitos Sociais e Controle Judicial no Brasil e na Alemanha - Os (Des)caminhos de um Direito Constitucional "Comparado". Sérgio Antônio Fabris Editor - Porto Alegre: 2002;

LEAL, Victor Nunes. Coronelismo, enxada e voto : o município e o regime representativo no Brasil / Victor Nunes Leal. — 4a edição - São Paulo: Companhia das Letras, 2012;

MAGIERA, Siegfried. El Derecho a una Buena Administración en la Unión Europea. Universidad de Ciencias de la Administración de Speyer.

http://www20.gencat.cat/docs/eapc/Home/Publicacions/Col_leccio\%20Materials/26\%20les\%20admini stracions\%20en\%20perspectiva\%20europea/8_Magiera/08\%20magiera_tradcast.pdf.

MIRANDA, Pontes de. Democracia, Liberdade, Igualdade (os três caminhos). São Paulo: Bookseller, 2002;

MORAIS, José Luis Bolzan de. Políticas públicas e jurisdição constitucional: entre direitos, deveres e desejos / José Luis Bolzan de Morais, Guilherme Valle Brum - Porto Alegre: Livraria do Advogado Editora, 2016;

NIETO, Alejandro; El desgobierno Judicial. $2^{\mathrm{a}}$ Ed. Madrid: Trota; 2005;

RODRÍGUEZ-ARANA, Jaime. El Derecho a uma buena Administración para los ciudadanos: um modelo global de administración. Oleiros (La Coruña) INAP, 2013;

ROSSEAU, Dominique; O Direito Constitucional contínuo: instituições, garantias de direitos e utopias. Revista de Estudos Constitucionais, Hermenêutica e Teoria do Direito (RECHTD) 8(3):261271, setembro-dezembro 2016 Unisinos - doi: 10.4013/rechtd.2016.83.01;

YEPES, Rodrigo Uprimny. Judicialization of politics in Colombia, International Journal on HumanRights 6:49, mimeografado, 2007, p. 57. 